\title{
COATLICUE, LA PIEDRA, LA PALABRA: SOMOS INDIAS. EN LOS RECUERDOS DEL PORVENIR Y BORDERLANDS: LA FRONTERA. THE NEW MESTIZA
}

\author{
Demetrio Anzaldo-González.
}

\section{(ब) $\Theta \Theta$}

Esta obra está bajo una licencia Creative Commons

Reconocimiento-No Comercial-Sin Obra Derivada 



\title{
COATLICUE, LA PIEDRA, LA PALABRA: SOMOS INDIAS. EN LOS RECUERDOS DEL PORVENIR Y BORDERLANDS: LA FRONTERA. THE NEW MESTIZA
}

\author{
COATLICUE, THE STONE, THE WORD: WE ARE INDIAS. IN LOS \\ RECUERDOS DEL PORVENIR AND BORDERLANDS. LA FRONTERA. \\ THE NEW MESTIZA
}

\section{Demetrio Anzaldo-González}

\begin{abstract}
RESUMEN
Esta revalorización del arte de la Coatlicue reelabora mitos y desmitificaciones mantenidos al interior de una cultura mexicana colonizada que no ha sabido aprender del pasado ni ha podido apreciar lo que la gran piedra muestra desde sus orígenes. El México oficial sigue cavando su propia tumba, re-negando y eliminando a los millones de pobladores autóctonos que las constantes migraciones han llevado al ahora monstruoso territorio mexicano que comercializa y vende todo incluido el arte del pasado. Pero, los tiempos y miradas siguen cambiando; ahora existen pensadoras y escritoras que llegan al centro de las discusiones y acciones en el mundo de las artes y ciencias que comparten otras visiones. Estas palabras y piedra siguen tiñendo de rojo (sabiduría) y negro (escritura), los silencios sonoros en la historia; porque el mundo también es de las mujeres y no sólo de los monstruos misóginos. La fuerza escultural de Coatlicue y la literatura de Elena Garro junto a los planteamientos epistemológicos de Gloria Anzaldúa muestran que si algo tienen de monstruosas sus obras/personas es que se han alimentado de los monstruos que andan desatados. Las solidarias y diferentes sociedades que potencializan con sus textos siguen siendo desafíos que esperan mejores respuestas. Palabras clave: Coatlicue, monstruo, mujer, masacre, México.
\end{abstract}

\begin{abstract}
The present artistic revalorization of Coatlicue, emphaticizes with the myths and deconstructed myths preserved internally by a colonized Mexican Culture that has never learned from its cultural past. It has never fully understood the art of this monolithic Stone since its origins. The Official Mexico keeps digging its own tomb, rejecting and killing millions of autochthonous inhabitants that have migrated to the now infernal Mexican territory. The Mexican Government commercializes and sales everything including the Works of its people. However, as the times keep changing, so too does the artistic appreciation of art. Today there are female writers and thinkers that contribute with their talents to the Arts and Science world. They share other interpretations and visions. Their words and the unique sculpture keep painting in red (wisdom) and black (writing), the historical sounds of silence. This is due to the fact that the world is also populated by women not just by the misogynistic monsters. The sculptural strength of Coatlicue, the Literary work by Elena Garro together with the epistemological statements by Gloria Anzaldúa show that if they have been considered as monsters it is because they have been fed with male monsters that are loose on the planet. They propose social solidarity and cultural differences in their texts; these are challenging works that are waiting for better readers/responses.
\end{abstract}

Key words: Coatlicue, monster, woman, massacre, Mexico.

Dr. Demetrio Anzaldo-González. University of Missouri. Associate Teaching Professor of Spanish. Department of Romance Languages and Literatures. Estados Unidos.

Correo electrónico:anzaldod@missouri.edu

Recepción: 06- 04- 2015

Aceptación: 19- 06- 2015 
¿Será verdad que la materia configura un cuerpo en el espacio; venas y huesos enlazados cantos, enlazando dolor a manos llenas?

(Fagundo, 1984)

\section{El cuerpo...}

En la Coatlicue, la de la falda de serpientes, la enorme piedra trabajada en todos sus ángulos por manos chichimecas, se materializan y enmarcan trazos, imágenes, espacios intangibles y formas simbólicas del pensamiento y de la vida física del mundo americano en donde ella es como una diosa-dios madre de la muerte, de la Tierra, vida y de todos los dioses:

\footnotetext{
Si la Coatlicue está decapitada es porque representa a la Tierra desgarrada en el origen del tiempo, a la tierra que reclama sangre y corazones como lo simboliza la falda de serpiente, la Tierra que devora los hombres, como lo indican los brazos levantados y las garras amenazadoras, el cuerpo listo a saltar, el collar de trofeos; manos corazones y cabezas de muerte. La diosa muere dando vida; es por tanto una mujer heroica vestida de insignias propias de los guerreros. Si los flujos de sangre brotando del cuello se transforman en serpientes, es porque las serpientes son la vida que se renueva, la fertilidad. (Graulich citado en Ortiz, 2014, párr. 17)
}

La enorme escultura concebida -en 1429 de acuerdo al calendario azteca o en 1454 según nuestra era- por mandato del Tlatoani azteca Izcóatl para glorificar el poderío cultural de la México-Tenochtitlán y dejar constancia histórica, fue una de las primeras construcciones/ creaciones pétreas en ser derribadas/sepultadas por los horrorizados españoles tras la matanza y destrucción del mundo Azteca. El terror nubla la mirada europea ante un mundo náhuatl desconocido/desconcertante, para ellos, pero lleno de una realidad que dignifica y defiende lo diferente y la diferencia entre ellos y la universal y mágica naturaleza; ese es el espacio múltiple/mítico/monstruoso al que alude la diosa de la vida y de la muerte por lo que optan por devolverla/envolverla a la tierra en la misma tierra a la que han bañado de sangre indígena. Al sepultarla, sin saberlo ellos mismos, le estarían dando otra fuerza mítica mucho mayor a la madre del sol y de la luna porque:

\footnotetext{
La muerte también encuentra su camino en las cuevas. Ellas, después de todo forman la entrada al inframundo, el cual no es solamente El Tlalocan, sitio de riquezas, sino también El Mictlan, La tierra de los muertos. Burgoa (1934: 336) [...] La cuevas al igual que las montañas y manantiales son lugares sagrados en todo el mundo. En México las cuevas han sido usadas para las ceremonias rituales siempre. Los ritos abarcan el ciclo de la vida humana y de sus fenómenos/particularidades; se siguen todos los pasos que van del nacimiento a la muerte. (Heyden, 2005, pp. 31-32)
}

Esto es algo que la misma vida de la estatua, en su increíble y recurrente renacer/acontecer, habría de comprobar a lo largo de su singular historia. Esta aparatosa obra de arte que rememora el mítico pasado mexica-chichimeca y que alberga/configura en su ser figuras y partes de animales entremezcladas con miembros y órganos humanos habría de seguir siendo descalificada como tal y estigmatizada, en cambio, como una de las monstruosidades más aberrantes hechas por los salvajes caníbales de la tierra conquistada; ironía en la vida del conquistador que ve al diferente y a su creación como monstruo y lo elimina para alimentar su propia bestialidad; puesto que no solo lo ha eliminado sino que lo descalifica y oculta autoimponiéndose una ceguera para ocultar su racismo e inclemente genocidio. Porque,

Ante este doble régimen de lo desapercibido se puede decir entonces que tanto el 'descubrimiento' del Nuevo Mundo como la invención de su monstruosidad inherente se corresponden simétricamente con el nacimiento de una nueva economía visual trasatlántica por un lado y con una cultura visual etnocéntrica propiamente capitalista y propiamente antropófaga por el otro. (Barriendos, 2008, p. 8) 
Los españoles, y por extensión los europeos, nunca supieron ver ni apreciar la grandeza de la vida de los indígenas ni de las diferentes culturas y espacios americanos. Raúl Zaffaroni lo ha entendido y planteaba hacia los años ochenta que:

La diferencia fundamental entre una cultura de las que llamamos primitivas y una de las evolucionadas es que las primeras no inventaron todavía la evasión. En ellas se acepta la vida y la muerte con naturalidad. A diario se afronta el miedo, el misterio, el amor, lo desconocido. El más allá habla constantemente. (Zaffaroni, 1985, p. 13)

Pero, al parecer, en el mundo actual siguen sin entender ni aprender de los mundos indígenas y originarios colonizados; siguen sin llevarlo a cabo, sin entenderle; además de insultarlo al mantener el agravio impune; porque nunca se ha pedido perdón por el genocidio y saqueo de los continentes ni castigado a los responsables de la pobreza, desigualdad social e injusticia históricas; sí en cambio:

\footnotetext{
[...] Dado el ritmo invasor (el desarrollo) de nuestra cultura, vía aventura, conquista o economía dominante (distintas figuras de una misma codicia) los evolucionados hemos devastado sus regiones y comercializado sus ídolos. Esto es, hemos quitado todo sostén, hemos desbaratado su individualidad y hemos profanado sus tradiciones. Pero eso sí, respetamos su hambre. El artista en general conjuga el tiempo de distinta manera que los demás hombres porque el pretérito está en el presente y el futuro al alcance de la mano. (Zaffaroni, 1985, p. 13)
}

Sacudiendo a esa mala actitud, soberbia incomprensión, rayada de ignorancia, esta creación escultural y mágica dentro de la conciencia y vida de los pueblos americanos llamada Coatlicue, deja su sepultura, para resurgir nuevamente en el año 1790, en el corazón del Virreinato de la Nueva España y del México Colonial. Sin embargo, esto ocurre por poco tiempo, puesto que se ordena su segunda muerte/entierro nuevamente por el temor de que la sola presencia del incomprendido monolito fuese la chispa que encendiera a sus millones de descendientes a levantarse en armas en contra de los injustos y racistas colonizadores aterrorizados por la escultura. Tendrían que pasar unos cuantos años más para que, en 1803, a petición, de Alejandro de Humbolt se le exhumara nuevamente. Humbolt, como sus antecesores, sintió terror al escrutar a la diosa-dios azteca, por lo que tras estudiarla minuciosamente, la volverían a enterrar en las tierras mexicanas las autoridades. Es Agustín de Iturbide el que mandará, más adelante, volver a desenterrar a la polémica y desafiante diosa que vuelve a reaparecer, pero ahora como una obra de arte, ante la mirada complaciente/naciente del México independiente. Tal pareciera que la piedra se negara a quedar/ser olvidada debajo de la tierra a no ser vista. A partir de ese momento no dejaría de estudiársele por pensadores, artistas y escritores de ambos lados del Atlántico. A través de los siglos, la diosa-dios ha ocupado/ desocupado espacios y clasificaciones nimias, ambiguas, cambiantes y diferentes alterando la vida y pensamiento de los que la observan y conocen. En años recientes, se siguen descubriendo aspectos y formulando hipótesis sobre la unicidad o multiplicidad del arte de la Coatlicue, así como de sus complejidades y mitos que abruman a los arqueólogos, historiadores y literatos al no precisar un significado definitivo para esta descomunal piedra a la que no logran denominar definitivamente. Por ejemplo, "Sobre su significado Leonardo López dice que es una diosa decapitada y amputada pero al mismo tiempo un ser pletórico de vida” (Figueroa, 2013, párr. 1). Es en suma un arte incomprensible o no comprendido como tal (Matos Moctezuma citado por Figueroa, 2013). "La carrera de la Coatlicue -de diosa a demonio, de demonio a monstruo y de monstruo a obra maestra-ilustra los cambios de sensibilidad que hemos experimentado durante los últimos cuatrocientos años" (Vidal-Lozano; Olarte y Lozano, 2004, párr. 5). Aludiendo a lo 
anterior y en consonancia con lo versado por el mismo Zaffaroni en su valioso artículo y como otra coincidencia epistemológica, se podría argumentar que ese arte de la Coatlicue desafía al mundo moderno; puesto que es: "[...] siempre vigente y actual; aunque pase milenios enterrado -bajo capas de arcilla o ignorancia- reaparecerá como nuevo e insondable en cada una de las confrontaciones que le brinde el desarrollo de la historia" (Zaffaroni, 1985, p. 13).

Esta intensa revalorización del arte o del desastre artístico de la Coatlicue es resultado de los mitos y desmitificaciones que se mantienen al interior de una cultura mexicana colonizada que tampoco ha sabido aprender del pasado ni ha podido apreciar lo que la gran piedra muestra desde sus orígenes: "una sagrada confraternidad" (Cáceres-Centeno, 2006, p. 150); puesto que, desgraciadamente, se mantiene también una todavía más opresiva colonización del pensamiento, palabra y obra americana de parte de los detentadores/dominantes de los poderes económicos, políticos, culturales y sociales. El México oficial sigue cavando su propia tumba, re-negando y eliminando a los millones de pobladores autóctonos que las constantes migraciones han llevado al monstruoso territorio mexicano y comercializado con sus manifestaciones artísticas las del presente y esas como la Coatlicue del pasado. Pero, los tiempos y las miradas siguen cambiando y ahora ya existen pensadoras y escritoras que llegan al centro de las discusiones y acciones en el mundo de las artes y ciencias que comparten otras visiones y otros planteamiento sin seguir la cortante otredad ni a la injusticia social impuesta imperialmente; puesto que,

\footnotetext{
A estas alturas del discurso, el poder ya no está en Dios-juez que preserva a la humanidad de la abyección reservando para él sólo el derecho de la violencia -violencia de la división y del castigo. En lo sucesivo el poder está en el discurso mismo, o más bien en el acto de juicio expresado por la palabra y, de manera más ortodoxa y mucho más implícita, por todos los signos que dependen de ella (poesía, pintura, música, escultura). Si bien estos signos no ahorran la necesidad de la confesión, despliegan la lógica de las palabras hasta en los pliegues más inaccesibles de la significancia. (Kristeva, 1980, pp. 174-175)
}

La calidad y certeza de la comunicación se manifiesta más ampliamente en un habla humana libre asentada/apoyada en la otra verdad que aportan las artes y como tal, la palabra humana vibra y reúne en el tiempo las particularidades de la vida artística de nuestros predecesores y predecesoras. El mundo admirado de la estatua revive mediante la mirada de la mujer y de su más completa forma de mirar y entender las culturas y las artes todas. Las cualidades y causalidades de las artes todas son comunicadas por un lenguaje inclusivo que se desprende del sexismo y maridaje patriarcal a pesar de que le están acompañándoles todo el tiempo. La escultura hecha por las manos anónimas del siglo XV también es un registro temporal del sentir del creador o creadores viviendo una existencia humana desconocida pero fija en el tiempo que proyecta el sentir de la comunidad. Las realidades y situaciones dadas en el momento de su creación siguen siendo recuperadas con los filtros del lenguaje, de la cultura y del espíritu de los seres humanos que ven más allá. Mas nunca podremos completarlas ni configurar esa manifestación perdida en el tiempo, sí en cambio, como todos los seres humanos seguimos compartiendo la certidumbre de la muerte y de la vida en nuestro estadio temporal. Mediante la memoria, el pensamiento, la energía, el vacío, el espacio, el habla y el tiempo sentimos el dolor y el temor de esos otros seres respetando sus (desconocidas/ conocidas) manifestaciones culturales y sus diferencias ancestrales que histórica, literal, y espiritualmente se van insertando en las diferentes etapas de nuestros procesos de vida al hacerlas parte también de nuestros universos existenciales.

La Coatlicue expresa ambas incertidumbres y costumbres de las realidades y visiones de sus creadores ante su vida y ante su muerte. La violencia vertida en un cuerpo que se concibe decapitado, del libre hacer/pacer de las serpientes en los universos múltiples, de la 
impresionante forma y razón de las garras de águila y de las entradas y salidas de los corazones, manos, cráneos y extremidades de un cuerpo tallado en todos los espacios y superficies de la diosa-dios azteca hablan de tiempos y espacios grandiosos y trágicos com-partidos por los diferentes grupos humanos de aquellos tiempos pasados. Es decir, por medio de la Coatlicue nos expresan no sólo su visión, su sentir y sus creencias sino una calidad de lo humano que se permuta/manifiesta en esa libertad con la que dotaron a una obra de arte en la que se reconocen llanamente en la piedra. Sí, aquellos hombres y mujeres de maíz tuvieron una idea clara de sus vidas y de sus muertes; puesto que en la estatua tallada con piedras ha quedado recreada esa mítica e histórica realidad múltiple, compleja, mágica y diferente. Esa implícita libertad en el vivir y en el hacer de los y las artistas chichimecas debería ser compartida y servir para liberar a sus congéneres y darles las bellezas de la vida que, desgraciadamente, sigue sin dárseles a los descendientes que yacen atrapados en el México de hoy. Al igual que sigue atrapada la piedra nacida de la piedra, la Coatlicue en esa otra tumba llamada Museo Nacional de Antropología e Historia en la agorera/agónica/racista y por ende monstruosa Ciudad de México. Si bien la Coatlicue se encuentra, de nuevo, encerrada entre grandes paredes de granito y acero, la población mexicana cercenada/cercada por un gobierno dictatorial sufre un terror indescriptible porque a su alrededor, las tumbas siguen acumulándose. Sí México es hoy por hoy una tumba gigantesca para la Coatlicue y su gente. Mucho se ha dicho acerca de la horripilante y desafiante escultura; pero hoy sabemos que los verdaderos monstruos andan sueltos y siguen llenado de innumerables tumbas clandestinas, para horror de la humanidad, todo el territorio nacional mexicano empapado con la sangre de su propia gente.

\title{
2. La palabra...
}

¿Será verdad que somos,
que hemos sido?
¿Será verdad que soñamos el mundo?

(Fagundo, 1984)

\begin{abstract}
El título de este ensayo es "Elena Garro escribió su 'porvenir' en Los recuerdos del porvenir". Helenita intervino en la entrevista para decir que su madre en la novela Los recuerdos del porvenir había profetizado el futuro de Elena Garro. La voz narrativa de esa novela, publicada en 1963, en la última página da la fecha del 5 de octubre como la fecha en que la protagonista es condenada, "convertida en piedra" (En Iguala, Guerrero se llamaban "piedras" a las prostitutas) Isabel Moncada". En la vida real, en la ciudad de México, la masacre de Tlatelolco sucedió el 2 de octubre. El día 5 de octubre, la misma fecha de la novela, Garro es condenada. (Toruño, 1999, pp. 30-31)
\end{abstract}

Como otra Coatlicue que no es entendida, en la historia, en la leyenda, la vida mítica de Isabel Moncada convertida en piedra en Los recuerdos del porvenir (1963) nos comunica también con las realidades pedregosas e inequidades de la vida nacional mexicana. Esta otra piedra-mujer convertida sacude, nuevamente, a las mitologías, a las teratologías, a las modernidades y al menosprecio que el mundo globalizado/monstruolizado actual le ofrece a la mujer que sabe defenderse a pesar de la cerrazón literal y física que sufre todos los días. Isabel Moncada nace entre las páginas creadas por otra mujer imponente/fuerte mucho más rebelde que Elena Garro y al igual que a la diosa-dios azteca, la de la falda de serpientes: Coatlicue, la incertidumbre y persecución que sufren ambas raya en la locura y también en el desprecio ante el desafío que estas mujeres le han planteado a todo lector que se atreve a leerlas, a verlas en el contexto real, mágico e histórico en el cual viven por siempre. 
Isabel Moncada nace y muere en el mismo lugar que la madre de la luna Coyolxauhqui en México-Ixtepec. Sin embargo, a diferencia de los monolitos descuartizados o decapitados esta mujer no pierde la cabeza ni se la reemplaza por otras dos cabezas de serpientes sino que usa la propia por partida doble y hace su voluntad al comandar a sus hermanos Nicolás y Juan Moncada, al pueblo entero a la rebelión/lucha en contra de los extranjeros al mando del general Francisco Rosas y al compartir su amor por este. Dueña de una prístina clarividencia y conocedora del incierto destino que se le ha impuesto/dominado, Isabel rebasa con creces al mundo en el que ha vivido; puesto que controla su vida y la vida de los que están a su alrededor sin importar edad, clase, sexo, nacionalidad ni religión. La personificación y el genio de esta joven bella rebelde tiene su origen no en las plumas míticas de la serpiente sino en las plumas magistrales que Elena Garro llena de tinta negra y roja para crear una doble flama de amor/pasión herencia dada por su padre y madre al procrearla a ella al personaje fantasmal y aterrorizante al cual ni su propia madre le podrá controlar:

\footnotetext{
-¡Es mala!... ¡Es mala!... - gritó Ana Moncada sintiéndose culpable de la maldad de su hija. Miró su cama con miedo y se oyó diciendo: “¿Vienes?” Con esa misma palabra había llamado Rosas a Isabel y su hija se fue con él en la oscuridad de los portales. Ella, después del nacimiento de Nicolás, había llamado a su marido cada noche: “¿Vienes?” Recordó aquellas noches; endulzaba la voz como Francisco Rosas y llamaba a Martín: “¿Vienes?” Y su marido sonámbulo avanzaba hasta su cama, hechizado por aquella Ana desconocida, y juntos veían aparecer el alba. “!Qué viva! ¡Qué bonita! ¡Se ve que la hicieron con gusto!” oyó decir a la comadrona que bañaba a Isabel recién nacida. "Las niñas hechas así, así salen”, agregó la mujer. (Garro, 1963, p. 239)
}

La mujer que nace como producto del amor libre, es así misma una mujer que sabe amar; puesto que para ello fue procreada en un mundo familiar violentado y corrompido por las foráneas fuerzas oficiales del orden militar y cristero enfrentadas/exhibidas en Ixtepec. Pero no sólo se deja amar, sino que ella también sabe decidir a quien amar sabiendo hacer prevalecer su voluntad; por eso,

\begin{abstract}
Isabel Moncada [...] se atreve a elegir vivir el amor o el desamor asumiendo las consecuencias de sus decisiones. Ella anhela, imagina, busca respuestas, se inconforma ante el hecho de quedar al margen de un porvenir de aventuras y experiencias. Isabel no puede ni quiere resignarse a pasar sus días entre las paredes de una casa. Rechaza la idea de ser considerada como una mercancía que pasa de las manos de sus padres a las de un hombre que le ofrezca la "comodidad" del matrimonio. (Olson, 2010, párr. 9)
\end{abstract}

Como la persistente piedra de río que va puliéndose/ transformándose, Isabel renuncia a quedar enterrada o encerrada entre otras piedras y le dice no al matrimonio, a los hábitos religiosos y a la cárcel en lo que han convertido su casa y por extensión su ciudad y su nación. En ese mundo la mujer que busca y que defiende su ser sufrirá el escarnio social y se perderá como una piedra/perdida más ante la imprudente pasividad de sus semejantes y por desobedecer un orden patriarcal repulsivo. Según Gregoria la vieja sirvienta, Isabel al igual que la Sara bíblica es castigada mediante la increíble metamorfosis/petrificación final de esta joven amante. Isabel renuncia a ser depósito, objeto, o rémora de la violencia masculina. Ella es su propia conciencia y defiende su independencia y sus ansias de amar y de vivir en libertad. Su valentía y fuerte oposición al mundo de los hombres y de las mujeres que viven en Ixtepec, se enmarcan en toda una serie de desplantes/desafíos a las autoridades ante la negligencia y cobardía del grupo humano que le rodea desde su nacimiento. Ella desafía también al mundo traído por los extranjeros y al mundo local enajenado y atemorizado. Sin volver a perder la cabeza emplea como estrategia los mitos, costumbres, tradiciones, miedos e ignorancia de las propias gentes de Ixtepec, junto con ese otro poder intrínseco al habla humana, el silencio en la 
mirada del que sabe, del que conoce lo pasado y porvenir, la que vive en ese presente eterno/ etéreo llamado sabiduría. Isabel desde pequeña supo de la importancia del tiempo, del saber decir las cosas a tiempo e imaginar lo que no existe, recordar/visualizar lo que pasará y decirlo solamente:

\begin{abstract}
-No pienso, oigo un chorrito de arena que cae dentro de mi cabeza y que me está cubriendo toda... [...] -Hay un muro que tapa mi casa y a mis hermanos... -Duérmete- suplicó Rosas, espantado por la palabra hermanos. Por el enrejado de la puerta se veía alta y clarísima la noche. Las estrellas brillaban solitarias; Francisco Rosas las miró con nostalgia y recordó el tiempo en que bajaban a su cama y corrían por el cuerpo de Julia luminoso y frío como un arroyo. Isabel las miró también. En otros tiempos la habían llevado al sueño de su casa. Trató de imaginar cómo era su otra casa, su otra vida, su otro sueño, y se encontró con su memoria olvidada. -Francisco, tenemos dos memorias... Yo antes vivía en las dos y ahora sólo vivo en la que me recuerda lo que va a suceder. También Nicolás está dentro de la memoria del futuro... (Garro, 1963, pp. 252-253)
\end{abstract}

Isabel aprende a decir sólo lo que necesita y considera importante. Su sentir es infalible lo que aumenta ese poder devengado por sus ancestros, conocidos y desconocidos. Su mirada y su hablar silente penetra a todo aquel que la conoce y a los que atemoriza al no poder conocerla enteramente. Ella conoce su naturaleza y muestra la fuerza de su propia voz a la que utiliza sabiamente para obtener todo aquello que se propone. Sus actos no tan sólo son los de una mujer hermosa, inteligente y dulce sino también los de una mujer rebelde, desafiante, viviendo una doble identidad/realidad en un eterno presente mítico, real e irreal en el cual se inmortaliza para siempre. Porque de hecho:

\footnotetext{
Había dos Isabeles, una que deambulaba por los patios y las habitaciones y la otra que vivía en una esfera lejana, fija en el espacio. Supersticiosa tocaba los objetos para comunicarse con el mundo aparente y cogía un libro o un salero como punto de apoyo para no caer en el vacío. Así establecía un fluido mágico entre la Isabel real y la Isabel irreal y se sentía consolada. “! Reza, ten virtud!”, le decían y ella repetía las fórmulas mágicas de las oraciones hasta dividirlas en palabras sin sentido. Entre el poder de la oración y las palabras que la contenían existía la misma distancia que entre las dos Isabeles: no lograba integrar las avemarías ni a ella misma. Y la Isabel suspendida podia desprenderse en cualquier instante, cruzar los espacios como un aerolito y caer en un tiempo desconocido. (Garro, 1963, p. 29)
}

Dueña de su cuerpo y de su palabra, Isabel Moncada actúa sin temor al futuro ni al pasado, sin miedo a la muerte puesto que ésta, es también su otra vida. Es una mujer que aún sin estar de cuerpo presente ni tener mitos antiguos como la Coatlicue, suscita controversias, loas, denostaciones y temores. Isabel Moncada, al igual que la Coatlicue, sigue siendo un dilema en el presente histórico, cultural y literario de México: “-¡Isabel! ¿Para quién bailas? ¡Pareces una loca!” (Garro, 1963, p. 18). Controladora de su espacio esta heredera de la madre de Huitzilopochtli, el colibrí zurdo, dios del sol y de la guerra y del sin par Quetzalcóatl la serpiente emplumada en el mundo americano, ejerce su ser/poder de mando como mujer mexicana consciente para plantear una batalla aunque sepa que está pérdida. Ante el terror impuesto por el nefasto general Francisco Rosas ella lo desafía y vence con su silencio pese a quedar envuelta en el doble juego mortal de su amante. Francisco Rosas mediante traiciones y denuncias logra que el pueblo se levante en contra de ella y la mantiene encerrada en el hotel Jardín. Isabel sufre el escarnio, la vituperación, de los moradores de Ixtepec y de la misma ciudad de Ixtepec abusada como ella misma. En este momento se hace patente/patética la descalificación humana a la hija de los Moncada a la que se le considera traidora, mentirosa, lujuriosa, hechicera, hipócrita, extranjera, en suma una mujer monstruosa en el sentir callado de la gente y del mismo general que ve que su amante es una piedra en su bota que le molesta pero que también le teme. El tiro planeado le ha salido por la culata y se convierte así mismo en 
la burla de ella y del pueblo entero que atestiguan como tanto Isabel como Julia han maniatado al bestial general de división:

\begin{abstract}
Cuando la llamó en los portales y se la llevó a su cuarto a sabiendas de que Juan estaba muerto y Nicolás en la cárcel de la guarnición, pensó en el triunfo total sobre Ixtepec. Ni siquiera sabía cómo era la joven que caminaba junto a él a medianoche. Al entrar a su cuarto y mirarla de cerca, le molestaron sus ojos obstinados y su traje rojo. A él le gustaban las mujeres suaves, envueltas en colores claros. La silueta rosada de Julia se interpuso entre él y la joven que lo miraba rencorosa, adivinando sus pensamientos. [...] Isabel obedeció sin replicar y Rosas, intimidado, apagó el quinqué de un soplo; en la cama se encontró con un cuerpo extraño que le obedecía sin decir una palabra. La luz de la mañana lo encontró desamparado. (Garro, 1963, pp. 245-246)
\end{abstract}

Los actos, acciones y desplantes que Isabel realiza ante las injusticias y hechos violentos en cada etapa de su vida configuran en su ser esa multiplicidad misteriosa que intimida como le ha sucedido al imponente general que se dobla ante ella. Isabel proyecta, desde su interior, a una mujer que vive en tiempos y realidades muy distintas, que vive y muere como la Coatlicue; porque Isabel Moncada es más que una valiente mujer rebelde que quiere tener la vida que ella misma escoja sin temor a nadie, por muy Rosas que sea, como lo ha atestiguado Gregoria ante la cual ésta, aprisionada Coatlicue-Moncada, se rebela para dictaminar su última palabra:

\footnotetext{
- ¡A Aunque dios me condene quiero ver a Francisco Rosas otra vez!

Su voz sacudió la colina y llegó hasta las puertas de Ixtepec. De sus ojos salieron rayos una tempestad de rizos negros le cubrió el cuerpo y levantó un remolino de polvo que volvió invisible la mata de pelo. En su carrera para encontrar a su amante, Isabel Moncada se perdió. (Garro, 1963, pp. 293-294)
}

La pérdida ficcional de Isabel no se debe entender como tal ni tampoco considerársele como una perdida mujer que muere por amor, sino la demostración de que es preferible vivir, hacer y decir en el mundo que le ha tocado en lugar de sufrir una injusta muerte en vida o guardar silencio ante la ignominia y la bestialidad. La muerte literaria de Isabel no podrá olvidarse fácilmente puesto que ella misma, su palabra, avanza más allá de la muerte y se catapulta hacia otra vida; porque, "para Garro, (Isabel) la presencia de realidades múltiples trasciende al lugar, al tiempo y a la identidad cultural debido a que todo esto ocurre en el lenguaje y no necesariamente en el lenguaje literario" (Biron, 2013, p. 81). La otra vida que ella misma ha elegido vivir como resultado de una sana rebeldía que defiende su voluntad y su lugar en un mundo que la aplasta y que mata a los que como ella defienden lo suyo, es la misma vida que tenemos los seres humanos puesto que es una sola a la que Isabel vuelve para ser la montaña donde se esconde la muerte.

\footnotetext{
En aquellos días empezaba una nueva calamidad política; las relaciones entre el Gobierno y la Iglesia se habían vuelto tirantes. Había intereses encontrados y las dos facciones en el poder se disponían a lanzarse en una lucha que ofrecía la ventaja de distraer al pueblo del único punto que había que obscurer: la repartición de tierras. Los periódicos hablaban de la "fe cristiana" y "los derechos revolucionarios". Entre los porfiristas católicos y los revolucionarios ateos preparaban la tumba del agrarismo. Hacía menos de diez años que las dos facciones habían acordado los asesinatos de Emiliano Zapata, de Francisco Villa y de Felipe Angeles, y el recuerdo de los jefes revolucionarios estaba fresco en la memoria de los indios. La iglesia y el Gobierno fabricaban una causa para "quemar" a los campesinos descontentos. (Garro, 1963, pp. 153-154)
}

Las matanzas en contra de los campesinos y verdaderos dueños de las tierras de parte de los poderes gobernantes al igual que se lee en la novela, -“vinieron otros militares a regalarle tierras a Rodolfito y a repetir los ahorcados en un silencio diferente y en las ramas de los mismos árboles" (Garro, 1963, p. 294) - continúan repitiéndose inmisericordemente en la actualidad. 
La importancia del sacrificio de Isabel rebasa el plano literario para incrustarse en lo histórico-real; puesto que con su vivir/morir ella muestra las injustas realidades de una Ixtepec dominada/destruida por los monstruosos militares mexicanos que inmolan/encarcelan a su propia población. Su grito de protesta se alza sobre el silencio oficial y social. La fuerza de la juventud/ voz humana de Isabel Moncada al final de su vida reitera/resalta lo dicho por su creadora en 1965, "Los moncada son los jóvenes mexicanos a los que no les permitimos ser científicos, marineros, investigadores, héroes en una palabra” (Mendoza, 1964). Hoy cincuenta años después, el habla literaria de Elena Garro vuelve a quedar revuelta por la tragedia humana; por el habla valiente de las voces jóvenes en Iguala, Guerrero, México. Son las voces de los jóvenes de Ayotzinapa que, al igual que las de los mundos visitados por la Coatlicue e Isabel Moncada, anhelan mejores espacios en un México real, piden ayuda al mundo. En la reprimida Iguala-Ixtepec, se enfrenta una maquiavélica cerrazón oficial y militar, homólogas del presente infernal que se vive en la maldita Iguala del México contemporáneo; en ambas, la literatura y la historia, nunca podrá olvidarse la presencia/audacia viva de los jóvenes defendiéndose ante la brutal y monstruosa injusticia mexicana; porque esas voces rebeldes, como lo fue la de Isabel Moncada-Elena Garro, se inmortalizan ante su propia tragedia humana rememorando a las voces ancestrales, que desde ultratumba denuncian el ominoso y recurrente genocidio que se vive en la Tierra de la Coatlicue en la infernal Ixtepec y en la de la densa y negra noche, Iguala.

\title{
3. El cuerpo y la palabra. Todas somos indias...
}

¿Será verdad que la materia configura un cuerpo en el espacio; venas y huesos enlazados cantos, enlazando dolor a manos llenas?

¿Será verdad que somos, que hemos sido?

¿Será verdad que soñamos el mundo?

(Fagundo, 1984)

\begin{abstract}
We need Coatlicue to slow us up so that psyche can assimilate previous experiences and process the changes. If we don't take the time, she'll lay us with an illness, forcing us to "rest." Come, little green snake. Let the wound caused by the serpent be cured by the serpent. The soul uses everything to further its own making. (Anzaldúa, 2007, p. 68)
\end{abstract}

Otra voz rebelde/contestataria va dejándose oír también por entre los vericuetos y encrucijadas de este camino-espectáculo dinámico conocimiento denominado Borderlands/ La frontera: The New Mestiza (1987) donde Gloria Anzaldúa deja fluir y hacer a sus sentimientos, memorias, mitos, imágenes y vivencias de un pasado que se problematiza ante este otro polémico acontecer epistemológico, tan antiguo como el planteado también por la Coatlicue e Isabel Moncada mundos opuestos e insurrectos, que continúan reverberando, pese al paso del tiempo. Así se expresa la propia Gloria Anzaldúa: "Muchos de los conceptos sobre la escritura y lo postcolonial son intentos por conectar las historias, valores y sistemas sociales precolombinos con la post-colonización del siglo XX" (Anzaldúa, 2000, p. 267). Esta inherente calidad literaria irreverente/desafiante del trabajo de Gloria Anzaldúa, es otro aspecto fundamental dentro de su propio discurso y perspectivas seminales exploradas en este ensayo, porque ella misma se ha rebelado ante los discursos dominantes o canónicos: "Me gustaría pensar que mi producción cultural -lecturas, ensayos, discursos, sueños-son todas acciones de 
resistencia a esa producción" (I'd like to think that my cultural productions -reading, writing, speaking, dreaming- are acts of resistance to that production) (Anzaldúa, 2000, p. 273). Para Gloria Anzaldúa el conocimiento de las culturas ancestrales es la base sobre la que sustenta una crítica directa ante el taimado modelo de la globalización imperialista y patriarcal que rechaza a estas otras visiones y actitudes de vida de los pueblos originales.

Esta yo chicana, femenina, híbrida, lesbiana, mestiza, mujer, la otra rebelde esperanzadora sigue siendo una debatible realidad epistemológica del presente, constatada por la importancia o el menosprecio que críticos tanto en Europa como de América le dan a este todavía inapresable ser discursivo/ corporal siempre en movimiento (Del Toro, 2005, p. 18). Estos puntos vibrantes, recalcitrantes y revolucionados gestándose al interior/exterior de la multiculturalidad mestiza dan luz a una literaria voz constantemente exacerbada/diferente; puesto que es con esta cambiante y polémica actitud escritural cómo Gloria Anzaldúa ha logrado trascender y trascenderse a ella misma siendo Mestiza-Nepantla-Coatlicue. Aludiendo al estudio de Shane Phelan, ella "la mestiza es definida por sus cambiantes territorios y sus identificaciones incompletas, pero la inestabilidad y la incomplitud de los territorios y las identificaciones no los vuelve menos "reales" que muchos que son unificadores" (Phelan, 1997, p. 213). Porque, "La artista es la intermediaria entre las variadas comunidades sociales de los mundos "normales" y nepantla en los "otros" mundos". (La artista is the mediator between various communities in the "normal" worlds and nepantla in the "other" worlds) (Anzaldúa, 2000, p. 268); desmitificando toda barrera simbólica/semántica con sus ideas, con sus acciones, con sus múltiples identidades fragmentadas y en constante proceso:

\footnotetext{
Cuando escribo siento que estoy esculpiendo en hueso. Se siente como si estuviera creando mi propia cara, mi corazón - una conceptualización náhuatl. Mi alma se hace ella misma por medio de este proceso creador. Ella está constantemente rehaciéndose y renaciendo a través de mi cuerpo. Es este aprender a vivir con la Coatlicue la que transforma la vida en las fronteras para cambiar una pesadilla en una experiencia numinosa. Es este estadio/sendero siempre algo más.
}

When I write it feels like I'm carving bone. It feels like I'm creating my own face, my own heart- a Nahuatl concept. My soul makes itself through the creative act. It is constantly remaking and giving birth to itself through my body. It is this learning to live with la Coatlicue that transforms living in the Borderlands from a nightmare into a numinous experience. It is always a path/state to something else. (Anzaldúa, 2007, p. 95)

Ese camino fragmentado, florido/sonoro, que ahora conocemos con mayor certeza, es donde su agitada ya atormentada vida resurge con cada palabra formando mundos reales e ideales. A lo largo de su vida va compartiéndonos sus miedos, sus desesperaciones, sus creencias, sus pasiones, sus esperanzas exacerbadas inmanentemente con lo visual, con lo racional y con lo sensual de una "yo" pasional/performativa inscripta en su literatura:

\footnotetext{
mis narraciones son actuaciones encapsuladas en el tiempo, reactuadas cada vez que son pronunciadas o silenciadas. Me gusta considerarlas como actos performativos y no como cosas sin vida, u objetos inertes (como en la estética occidental consideran al arte).

my "stories" are acts encapsulated in time, "enacted" every time they are spoken aloud or silently. I like to think of them as performances and not as inert and "dead" objects (as the aesthetics of Western culture think of art works) (Anzaldúa, 2007, p. 89)
}

Ese ir a algo más que le brinda la energía o estadio de la Coatlicue a Gloria le permite libremente recrearse en su cuerpo/palabra: "Tallo mi cuerpo como si estuviera lavando un trapo. Toco las saltadas venas de mis manos, mis chichis adormecidas como pájaras al anochecer..." (Anzaldúa, 2007, p. 93) Haciendo eco de lo ya anunciado en su "Movimientos de rebeldía y 
las culturas que traicionan" en donde cita: "Pero yo, como otras personas queer, soy dos en un único cuerpo, tanto hombre como mujer. Soy la encarnación de los hieros gamos: la unión de contrarios dentro de un mismo ser" (Anzaldúa, 2007, p. 41). Es decir, un estadio diferente en el que se reconoce también como la otra entidad cosmogónica a la que se une como una imagen otra: la Coatlicue-Anzaldúa:

\footnotetext{
I first saw the statue of life-in-death and death-in-life, headless "monster" goddess (as the Village Voice dubbed her) at the Museum of Natural History in New York. She has no head. In its place two spurts of blood gush up, transfiguring into enormous twin rattlesnakes facing each other, which symbolize the earth-bound characgter of human life. She has no hands. In their place are two serpents in the form of eagle-like claws, which are repeated at her feet: claws which symbolize the digging of graves into the earth as well as the sky-bound eagle, the masculine force. Hanging from her neck is a necklace of open hands alternating with human hearts. The hands symbolize the act of giving life, as well as the pain that humans suffer throughouth life in their struggle for existence. The hearts aslo represent the taking of life through sacrifice to the gods in exchange for their preservation of the world. In the center of the collar hangs a human skull with living eyes in its sockets. Another identical skull is attached to the belt. These symbolize life and death together as part of one process. (Anzaldúa, 2007, p. 69)
}

La intensidad de esta palabra mestiza desplazándose, libremente/involuntariamente, en medio del estadio de la antigua oralidad vertida en la página en blanco le sirve para hacer evidente/ para expresar ese algo más que ha revitalizado a estas historias personales y colectivas tensionadas en el tiempo haciéndose una con la divinidad azteca y sus múltiples metamorfosis, haciendo realidad el deseo de la autora de que al igual que ella se condensa en la Coatlicue, su palabra en Borderlands fuese una voz diferente, a la vez que personal, única, solidaria para cada una de sus lectoras con quienes también comparte ese pasado sentir para hacerlo parte de un presente doble atemporal y cierto:

\footnotetext{
Como ciudadanos del mundo aprendemos a conducirnos entre las culturas, países y costumbres. El futuro les pertenece a aquellos que cultivan las sensibilidades culturales las diferencias y a esos otros que usan esas habilidades para forjar una concientización híbrida que trascienda mentalmente ese "nosotros" en contra del "ellos" y nos lleven a una posición de nosotras conectando los extremos de nuestras realidades culturales.
}

As world citizens we learn to move at ease among cultures, countries, and customs. The future belongs to those who cultivate cultural sensitivities to differences and who use these abilities to forge a hybrid consciousness that transcends the "us" versus "them" mentality and will carry us into a nosotras position bridging the extremes of our cultural realities. (Anzaldúa, 2000, p. 255).

Las luminosas/oscuras y coloridas palabras rojas híbridas compuestas desde ese lugar de en medio, Nepantla, muestran no sólo la imbricación del pasado/presente y del español, inglés o náhuatl, sino al shamanístico doble juego ontológico/onírico en conjunción con el proteico/dinamismo utópico de una voz errante e irreverente. Son estas mismas voces, ideas, sueños e historias narradas con las silentes/sonoras tintas negras y rojas de la escritura y la sabiduría usadas por Gloria Anzaldúa las que son también re-creadas en los mundos históricos y literarios del presente, de su presente y del momento que compartimos con cada una de sus y nuestras propias historias, her stories, sus trances, los trances otros:

Mis sueños despierta son sobre los cambios. Cambios al pensar, cambios en la realidad, cambios genéricos: una metamorfosis tras otra en un mundo donde la gente vuela por el aire, sana de sus heridas mortales. Yo estoy jugando conmigo misma, estoy jugando con el alma del mundo. Soy el diálogo entre mi ser, estoy jugando con el alma del mundo, soy el diálogo entre mi yo y el espíritu del mundo. Me cambio a mí misma, cambio al mundo.

My "awakened dreams" are about shifts. Thought shifts, reality shifts, gender shifts: one metamorphoses into another in a world where people fly through the air, heal from mortal wounds. I am playing with 
my Self, I am playing with the world's soul. I am the dialogue between my Self, I am playing with the world's soul, I am the dialogue between my Self and el espíritu del mundo. I change myself, I change the world. (Anzaldúa, 2007, p. 92)

La grandilocuente fuerza contestataria, la elocuente grandiosidad de este pensamiento mítico/nemotécnico/visual es portentosa:

\begin{abstract}
Escribo los mitos en mí, los mitos soy yo, los mitos que quiero llegar a ser. La palabra, la imagen y las emociones tienen una energía palpable, una especie de poder. Con imágenes domo mi miedo, cruzo los abismos que tengo por dentro. Con palabras me hago piedra, pájaro, puente de serpientes arrastrando a ras del suelo todo lo que soy, todo lo que algún día seré.

I write the myths in me, the myths I am, the myths I want to become. The word, the image and the feelings have a palpable energy, a kind of power. Con imágenes domo mi miedo, cruzo los abismos que tengo por dentro. Con palabras me hago piedra, pájaro, puente de serpientes arrastrando a ras del suelo todo lo que soy, todo lo que algún día seré. (Anzaldúa, 2007, p. 93)
\end{abstract}

Esta palabra/mujer mítica sigue tiñendo de grana y ébano, los silencios sonoros de la página en blanco. Son esas imágenes/metáforas nunca completadas las que convierten nuestros y sus pensamientos, nuestras y sus emociones, transformando ideas, llevándonos a nuevos horizontes dentro del pensar y del sentir. En Borderlands se proyecta esta escritura apasionada que revierte conceptualizaciones y potencializa significantes; es una escritura llena de sacrificios de sangre pasional, constantemente, tensionada, transformada, formada o deformada por las diferentes visiones de mundo que se intentan deshabitar o habitar; porque,

\footnotetext{
Este es el sacrificio que el acto creador necesita, un sacrificio sangriento. Puesto que a través del cuerpo, al arrancándose la carne, puede el ser alma humana ser transformada. Y para que las imágenes, las palabras y las narraciones tengan este poder transformador, deben desprenderse del cuerpo humano -de carne y hueso- y dar forma al cuerpo del planeta, de la piedra, del cielo, del agua, de la tierra.

This is the sacrifice that the act of creation requires, a blood sacrifice. For only through the body, through the pulling of flesh, can the human soul be transformed. And for images, words, stories to have this transformative power, they must arise from the human body -flesh and bone- and form the Earth's body-stone, sky, liquid, soil. (Anzaldúa, 2007, p. 97)
}

Son las diferentes realidades/representaciones de los yos múltiples, repitiéndose al infinito; como proyectándose en una serie interminable de espejos distorsionándose entre los espacios estudiados/vividos y los tiempos pasados y presentes consumiéndose en la palabra dictada por Gloria Anzaldúa, voz en la que reconoce ese juego infinito del estar o del no estar en el mundo; el dilema eterno del ser y del no ser dentro de los múltiples espacios, vacíos, silencios, palabras, energías, materias, voluntades y tiempos del quehacer y ser humanos que le brinda su misma totalidad:

\footnotetext{
I can't seem to stay out of my own way. I've always been aware that there is a greater power than the conscious I. That power is my inner self, the entity that is the sum total for all my reincarnations, the godwoman in me I call Antigua, mi Diosa, the divine within, Coatlicue-Cihuacoatl-TlazolteotlTonantzin-Coatlalopeuh-Guadalupe- they are one. (Anzaldúa, 2007, p. 72)
}

Esta Antigua, mi diosa, chicana, femenina, híbrida, lesbiana, mestiza, mujer, la otra Coatlalopeuh, la rebelde Coatlicue, esa otra mujer pensante... sigue siendo una esperanza en la América del Norte. La incertidumbre de la Coatlicue sigue emergiendo sobre la tierra puesto que no deja de ser una debatible realidad epistemológica que desestabiliza al mundo occidental: "puesto que en ella encarnan todos los procesos del Cosmos" (Anzaldúa, 2007, p. 68). Había sido vislumbrada/presentida y, tal vez, también recordada por Gloria desde sus comienzos con esa breve re-memorización temprana a una infancia inscrita especular/espectacularmente en la memoria y un discurso epistemológico desafiante/diferente ante la monstruosa realidad 
enfrentada como una mujer mestiza; pero ahora retoma una mayor significación cuando se enfrenta a su indescriptible e inatrapable realidad/corporalidad, a sus mitos y transformaciones para hacer ella misma su palabra y su propia persona:

\footnotetext{
I see oposición e insurrección. I see the crack growing on the rock. I see the fine frenzy building. I see the heart of anger or rebellion or hope split open that rock, releasing la Coatlicue. And someone in me takes matters into our own hands, and eventually, takes dominion over serpents-over my own body, my sexual activity, my soul, my mind, my weaknessess and strengths. Mine. Ours. Not the heterosexual white man's or the colored man's or state's or the culture's or the religion's or the parents' -just ours, mine. (Anzaldúa, 2007, p. 73)
}

Gloria Anzadúa, al igual que Isabel Moncada-Elena Garro, se yergue por sobre la fallida y monstruosa opresión y racismo impuesta a su condición de mujer pobre, marginada, oprimida y rechazada. Aprende de sus raíces y de sus solidarias compañías y estudia a los que como ella creen en las cosmogonías y facultades de los espíritus rebeldes y sabios. Alza la voz para fustigar al mundo patriarcal injusto para romper las piedras donde se asienta un conocimiento parcial e inexacto y hace sentir su presencia utilizando mitos y creencias americanas y universales a las que vuelve a traer a la tierra, rompiendo con ellas las demás piedras que sostienen a un mundo Occidental que continúa resquebrajándose ante el regreso de la serpiente emplumada y sus ascendientes.

Estas palabras y piedras siguen tiñendo de rojo (sabiduría) y negro (escritura), los silencios sonoros en la página en blanco; porque el mundo también es de las mujeres y no sólo de los monstruos. La fuerza escultural de la Coatlicue y la literatura de Elena Garro junto a los planteamientos epistemológicos de Gloria Anzaldúa revierten y muestran que si algo tienen de monstruas sus obras/personas es que se han alimentado realmente de monstruos. Las solidarias y diferentes sociedades que potencializan son un desafío que espera respuesta. Son estas imágenes/metáforas de lo escrito/descrito por Elena Garro, Gloria Anzaldúa y del pétreo disentir artístico de la inatrapable Coatlicue nunca completadas, las que convierten nuestros y sus pensamientos, nuestras y sus emociones, en pensamientos transformadores de ideas que nos ayudan a visitar éstos y esos otros horizontes artísticos y humanos inexplorados, cuestionando, el ver, el pensar, el sentir y el disentir siempre buscando un más allá ante las epistemologías y creaciones humanas.

\section{Bibliografía}

Anzaldúa, G. E. (2000). Interviews/entrevistas. Keating, A. (Ed.). New York: Routledge.

Anzaldúa, G. E. (2004). Movimientos de rebeldía y las culturas que traicionan. http://www. lahaine.org/ [Consulta 20 de marzo de 2015].

Anzaldúa, G. E. (2007). Borderlands/La Frontera: The New Mestiza. (3 ed.). San Francisco: Aunt Lute Books.

Barriendos, J. (2008). Apetitos extremos. La colonialidad del ver y las imágenes-archivo sobre el canibalismo de Indias. https://elpaisinvisible.wordpress.com/ [Consulta 29 de marzo de 2015].

Biron, R.E. (2013). Elena Garro and Mexico's Modern Dreams. USA: Bucknell University Press.

Cáceres-Centeno, G. (2006). La escritura y el discurso del mito en la cultura. Devenires. 7 (14), 130-153. 
Del Toro, A. (2005). Figuras de la hibridez: Carlos Fuentes, Guillermo Gómez Peña, Gloria Anzaldúa y Alberto Kurapel. [pdf]. http://home.uni-leipzig.de/ [Consulta 29 de marzo de 2015].

Fagundo, A. M. (1984). Como quien no dice voz alguna al viento. Santa Cruz de Tenerife: Pubicaciones de la Caja General de Ahorros.

Fagundo, A. M. (1994). El sol, la sombra, en el instante. Madrid: Editorial Verbum.

Figueroa, A. (2013, 23 de febrero). Trazan la ruta histórica de las cinco grandes esculturas mexicas. Crónica al momento. http://www.cronica.com.mx/notas/2013/732866.html [Consulta 25 de marzo de 2015].

Garro, E. (1963). Los recuerdos del porvenir. México, D. F.: Lecturas mexicanas (SEP).

Heyden, D. (2005). Rites of Passage and Other Ceremonies in Caves. Por J. E. Brady y K. M. Prufer (Eds.). In the Maw of the Earth Monster: Mesoamerican Ritual Cave Use. (21-34). Austin: University of Texas Press.

Kristeva, J. (1989) Poderes de la perversión. México: Siglo XXI Editores.

Mendoza, M. L. (1964, 13 de enero). El porvenir de los recuerdos. El Día, 13.

Olson, A. (2010, 29 de enero). Elena Garro: Coloso de la literatura mexicana. Letra sanguíenea. Bitácora de poesía. http://anrratolson.obolog.es/ [Consulta 18 de marzo de 2015].

Ortiz-García, E. (2014, 17 de julio). La Coatlicue y su simbolismo. Proyecto Diez periodismo con memoria. http://www.proyectodiez.mx/estilodevida/culturayentretenimiento/ [Consulta 25 de marzo de 2015].

Phelan, S. (1997). Lesbianas y mestizas: apropiación y equivalencia. Playing with Fire: Queer Theories, Queer Politics. (197-224). New York: Routledge.

Toruño, R. (1999). Elena Garro escribió su 'porvenir': en Los recuerdos del porvenir. Por M. L. García y R. K. Anderson. Baúl de recuerdos. Homenaje a Elena Garro. (23-34). México: The University Press of Tlaxcala.

Umanzor, M. A. (1996). La visión de la mujer en la obra de Elena Garro: El árbol, Los perros, Los recuerdos del porvenir, Testimonios sobre Mariana y La casa junto al río. Miami: Ediciones Universal.

Vidal-Lozano, M.; Olarte, A. y Lozano, M. (2004). Pasado y presente precolombino. Revista de Artes. 3. http://www.revistadeartes.com.ar/ [Consulta 18 de marzo de 2015].

Yuval-Davis, N. (1997). Gender and Nation. Great Britain: Sage Publications.

Zaffaroni, R. (1985, 6 de junio). El capítulo que faltaba. Jaque. Revista Semanario. Montevideo. 